\title{
Smart water quality monitoring system
}

\author{
Shubham Srivastava ${ }^{1}$, Anupam Verma ${ }^{2}$, Dr. $N$ k Saxena ${ }^{3}$ \\ ${ }^{1}$ Student, Geotechnical \& Geoenvironmental Engineering, Knit Sultanpur (U.P.), India \\ ${ }^{2}$ Assistant Professor, Department Of Civil Engineering, Knit, Sultanpur (U.P.), India \\ ${ }^{3}$ Professor, Department Of Civil Engineering, Knit, Sultanpur (U.P.), India
}

\begin{abstract}
Water is the most widely used matter present on earth, due to urbanization industrialization, and pollution the availability of fresh water for drinking becomes scarce. Management of fresh water should be done strictly for a safe future. The conventional method of monitoring water quality is a slow and expensive process. In addition, this monitoring method is not suitable for rural and remote areas where analytical laboratories and technical personnel are not available. Current testing approaches are time-consuming and require 18-24 hours to give a result. The equipment used in this method is bulky to transport to remote locations, very complex to use and requires specialized professionals to perform the tests. Although these processes are carried out by field experts, precise monitoring of water quality using chemical reagents and specialized laboratory equipment is complex and not completely reliable. The sensor-based monitoring technology has solved many difficulties associated with the monitoring of many elements such as air quality monitoring, noise level monitoring, and flood monitoring in the modern world. Real-time monitoring, of a flood, sewer monitoring, and rubbish collection are all done via sensor-based systems connected to the internet. Water quality monitoring in rivers, lakes, and underground water can be done by using sensor-based smart monitoring techniques. In this research work, a sensor-based smart technique is used for water quality (ph, turbidity, temperature) and quantity (water level) monitoring for river tamsa.
\end{abstract}

Keywords: sensors, water quality, smart monitoring, real time monitoring

\subsection{INTRODUCTION}

On the surface of the earth, the distribution of water is unequal. Freshwater quantity have just up to just 2.8 percentage of the water on the surface; the rest 97.2 percent is in the ocean, which is saline in nature, not fit for drinking purposes. Freshwater found in glaciers is 69 percent of total freshwater present on earth, which is trapped and cannot be used for drinking purposes. 30 percent water of freshwater, present in rivers, springs, and lakes, and water bodies, as water that may become a source of fresh water.

The availability of freshwater which can be used for drinking purposes is only $0.8 \%$ of the total available fresh water available on the earth's surface. $0.62 \%$ of total earth water is present as groundwater below the surface of the earth, the remaining percentage of water is present in form of the subsurface water in river lakes and water bodies.

The provision of clean water is a priority in the constitution of india, and article 47 gives the state a duty to provide clean water and improve public health standards. To ensure the quality of supply water according to drinking water standards, it is necessary to monitor in real-time for rapid and accurate quality examine.

India's potential cost to fight waterborne diseases is estimated to be over hundred million per year. This is especially true in drought-prone areas, which have affected a third of the country in the last two years. Only around half of india's population has access to properly regulated drinking water. 1.96 million households use chemical contaminated water, primarily from fluoride and arsenic. Regular monitoring of drinking water in real-time is required to ensure about the water consumed by the consumer is fit for drinking purposes.

Water quality must conform to specific guidelines and be checked regularly. Sensor based monitoring opens up new options for monitoring water quality. Connected devices can be placed in strategic locations such as near a raw water source, near a water treatment plant, and at a residence. These sensors can continuously monitor water parameters and connect with a system that will notify authorities if a risk is identified related to contamination of water.

\subsection{LITERATURE REVIEW}

Shruti sridharan developed a low-cost wireless sensor network for monitoring water quality parameters such as turbidity, temperature, the ph level of water, in real-time. This wireless sensor network is based on the high power zigbee technology with ieee 802.15.4 [1]

Troy, s m et al. (2002) use eco mapper an underground vehicle for mapping the quality of underground water. The drawback of this system is that it has a small life span of 8-14 hours with a low speed of traveling. For the operation of this system, human help is required, in underground contaminated water monitoring is not safe for human health. [2] 


\section{International Advanced Research Journal in Science, Engineering and Technology}

\section{Vol. 8, Issue 11, November 2021}

\section{DOI: 10.17148/IARJSET.2021.81103}

Peter, g (n.d) introduced a digital camera for monitoring protozoa and biological pollution which is placed in sampling water. By this system of monitoring, the classification of pollution cannot be performed without applying further analysis. Robotic fish can be used for the better monitoring of biological and chemical pollution in underground water.[3]

$\mathrm{R}$ karthik kumar, et al. Investigated underwater wireless sensor network technology for monitoring water quality parameters, which is powered by a solar panel. Through wireless sensor network data such as ph turbidity and oxygen level in water is collected, and send to the monitoring station. At the monitoring station receiver collect the data and displays, data collected by the sensor is further analysed by using the simulation technique.[4]

Daudi s. Simbeye and shi feng yang presented, a wireless sensor network for aquaculture to detect and control the water quality parameters such as temperature and water level in real-time. Zigbee wireless communication standard is used for transmitting the data collected by node of sensor, host computer uses lab view software platform for data analysis, processing, and presentation. The owner receives the data of water quality parameters in form of short notification from the base via the global system of module notification. If due to the temperature rise, the dissolved oxygen gets depleted then the pump can be auto-started, to maintain the oxygen level and water level in a pond, for avoiding fish kills. The system has the advantage that the water quality parameter can be monitored by reducing the cost of monitoring.[5]

Brinda das, p.c. Jain proposed "real-time water quality monitoring using internet of things. They suggested the traditional way of water quality parameter testing requires, any number of samples of water and then tested in the lab by a skilled person. This method of water quality parameter monitoring is time-consuming and requires a skilled person and the cost of monitoring is more compared to the monitoring of water quality parameters by using the various sensor. They used the zigbee module to transfer the data from the sensor to the microcontroller wirelessly, and further, the data is transferred by the microcontroller to a smartphone by using the gsm module. An official can monitor the change in the water quality parameter, if water quality gets polluted then immediate action can be taken.[6]

Nikhil r, et al. Presented a smart device for water quality parameter monitoring based on iot technique, the quality of water is easily monitored utilizing collecting the water parameter data. They use a ph sensor, water level sensor, turbidity sensor, and conductivity sensor for collecting the data of parameters. The sensor used in the system collects the data and sends it to arduino uno, wi-fi -module is used for transmission of data to the user. This system minimizes the time and cost required for the detection of water quality parameters.[7]

Punit et al. Proposed iot based water quality monitoring system based on raspberry pi3 development board programmed with python framework, and mat plot lab library is used for plotting water quality parameters. They used temperature, ph, electrical conductivity, and dissolved oxygen sensor for water parameter monitoring, all sensors are calibrated with reference solution before testing to reduce the measurement uncertainty. The advantage of the proposed system is that they use raspberry pi for iot implementation which consumes low power by using real-time monitoring for various applications such as pound lake and river water rapid monitoring and contamination detection can be done easily.[8]

Mohammad salah et al. (2019) presented a water quality monitoring system based on a wireless sensor network in which real-time monitoring is done by data collection at remote areas by the sensor, the monitoring can be done at a remote area by accessing the data of water quality. If obtain a value of the parameter is above the threshold value an alert notification will be sent to the authorized person. Neural network classification on water parameters is used to predict the water quality as good or bad. Classification is based on the hadoop cluster neural network which has the advantage that neural networking is based on an artificial neural network that is good for nonlinear relationships and learning.[9]

Vaishnavi et al. (2017) developed low-cost devices based on iot for real-time monitoring of water quality for real-time, monitoring of water quality, they use the various sensor for measuring the water parameter as a chemical parameter, physical parameter, and flow, measurement of these parameters is done by using the various sensor as temperature sensor turbidity sensor and flow sensor core controller arduino model is used for the processing the data, by using wi-fi module, water parameter at an instant can be view on screen with the help of internet. Arduino used in this system is programmed on embedded c language which converts the analog value given by the sensor into a digital value and display shows the output value.[10]

Gowthamy j et al. (2018) they developed a real-time monitoring system of drinking water by using iot technology various sensors as flow sensors for flow measurement temperature, turbidity, and ultrasonic sensor for monitoring physical quality parameter monitoring and ph sensor for detection of how acidic and basic water is used, data generated by the sensor is control and process with the help of arduino, a wi-fi module transfer the data to the user internet which is 
Vol. 8, Issue 11, November 2021

DOI: 10.17148/IARJSET.2021.81103

connected to arduino. Change in water quality parameters can be easily observed and data collected by the system can be used for analysis. [11]

\subsection{METHODOLOGY}

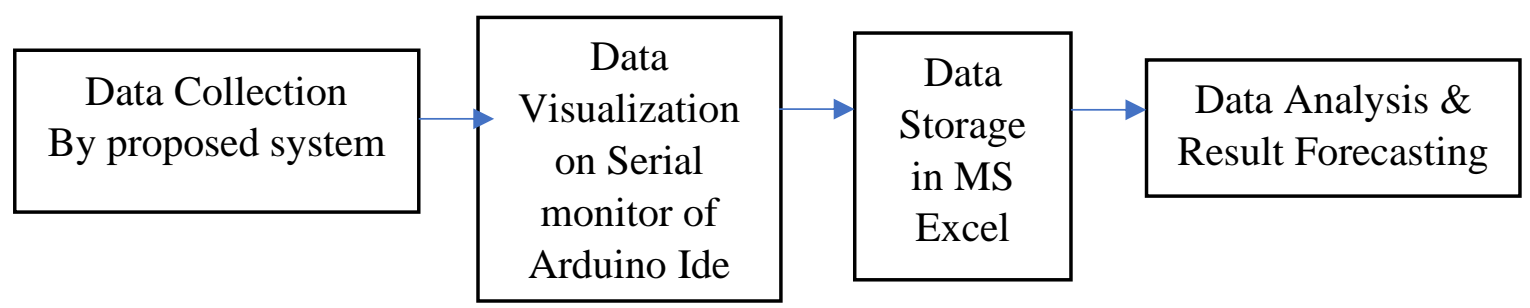

\section{1 proposed system}

We have used various sensors for the measurement of water quality parameters and the measurement of flow parameters. $\mathrm{Ph}$ sensor, turbidity sensor, the temperature sensor is used for the measurement of water ph level, turbidity, and temperature respectively. For the measurement of water flow parameters, we have used an ultrasonic water level sensor. These sensors are connected with the arduino, which works as a core controller device, and arduino is connected to the wi-fi module which processes the data.

\section{Block diagram of proposed system}

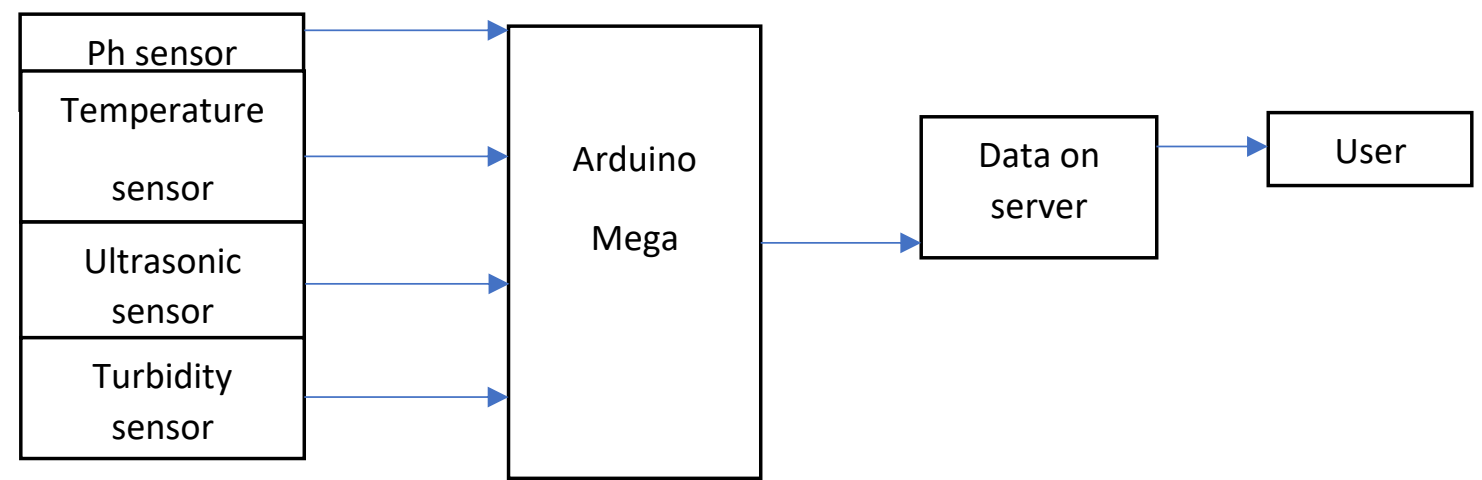

\subsection{1 arduino}

Arduino is a company that deals with software as well as hardware component they design single-board microcontrollers and processor kits for building digital devices. Arduino board contains many sets of digital and analog pins for interfacing various boards and sensors. Serial communications interfaces, including universal serial bus (usb) on some versions, are provided on the boards, which are also utilized for software loading. The c and c++ programming languages, as well as a common api, are known as the "arduino language," which may be used to program the microcontrollers.

\subsection{2 ph sensor}

The ph sensor is made of a glass membrane in which a known ph buffer solution is filled, which ph value is typically 7. During the test when a probe of ph sensor is dipped into the water a potential difference exists due to the hydrogen iron exchange in liquid of ph probe, with the positive charge ions of glass membrane. Amplifier module measures this potential difference and converts it to ph value.

\section{Table 1. Gravity ph sensor specification}

\begin{tabular}{|c|c|}
\hline Gravity ph sensor specification & analog gravity ph sensor \\
\hline $\mathrm{Ph}$ measurement range & Operating temperature \\
\hline Operation voltage & $\pm 0.1 @ 25^{\circ} \mathrm{c}$ \\
\hline
\end{tabular}

\subsection{3 temperature sensor}

For temperature measurement of water we used ds18b20, which is a 1-wire waterproof sensor device, it can measure the temperature of soil and chemical solution in an adverse environment like for measurement of the temperature of high acidic or basic solution. 
Vol. 8, Issue 11, November 2021

DOI: 10.17148/IARJSET.2021.81103

Table 2. Temperature sensor specification

\begin{tabular}{|c|c|c|c|}
\hline Temperature sensor & & Device name & ds $18 b 20$ \\
\hline Measurement range & $0-14$ & Operating temperature & -55 to $125^{\circ} \mathrm{c}$ \\
\hline Operation voltage & & Accuracy & $\pm 0.5^{\circ} \mathrm{c}$ \\
\hline
\end{tabular}

\subsection{4 ultrasonic sensor}

For measurement of water level, we use an ultrasonic sensor, which is a non-contact length measuring module .an ultrasonic sensor measures distance, by calculating the lag time between the transmitted and received a wave of ultrasonic sound. The transmitter emits the wave and if any obstruction occurs in the path of the wave, it reflects the transmitted wave, and the receiver of the sensor picks it, by multiplying the lag time with the velocity of sound in the air we can easily calculate the distance between obstruction and ultrasonic sensor.

Table 3. Ultrasonic sensor specification

\begin{tabular}{|c|c|c|}
\hline Ultrasonic sensor specification & Device name & hc-sr04 \\
\hline Measurement range & Measurement angle & 15 degree \\
\hline Operation voltage & Frequency & $40 \mathrm{hz}$ \\
\hline
\end{tabular}

\subsection{5 turbidity sensor}

The gravity arduino turbidity sensor monitors the quality of water by measuring turbidity, often known as opaqueness. It detects suspended particles in water by measuring light transmittance and scattering rate, which change with the total suspended solids (tss) concentration in the water. As the tts increases, so does the quantity of liquid turbidity. Turbidity sensors are used to evaluate river and stream water quality, as well as wastewater and effluent assessments, settling pond management devices, sediment transport investigations, and laboratory tests. This liquid sensor may generate analog as well as digital signals.

Table 4. Turbidity sensor specification

\begin{tabular}{|c|c|c|c|}
\hline \multicolumn{2}{|c|}{ Turbidity sensor specification } & Device name & sku, sen0189 \\
\hline Operating temperature range & 5 to $90^{\circ} \mathrm{c}$ & Output method & analog and digital \\
\hline Operation voltage & & Response time & $500 \mathrm{~ms}$ \\
\hline
\end{tabular}

\subsection{6 interfacing sensors with arduino}

We interface ultrasonic ,turidity, ph and temperature sensor with arduino, as given in the table, the hardware setup and its connection are shown in fig 1. For data transferring between sensors to arduino c++ programming language is used. The values of the various parameter of water quality can be viewed on the serial monitor and serial plotter of arduino ide. For data analysis purposes arduino is connected to the ms excel with the help of the data streamer function provided by microsoft 365.

\begin{tabular}{|c|c|c|c|c|c|c|c|}
\hline $\begin{array}{l}\text { Ultrasonic } \\
\text { sensor pin }\end{array}$ & $\begin{array}{l}\text { Arduino } \\
\text { pin }\end{array}$ & $\begin{array}{l}\text { Turbidity } \\
\text { Sensor pin }\end{array}$ & $\begin{array}{l}\text { Arduino } \\
\text { pin }\end{array}$ & $\begin{array}{l}\mathrm{Ph} \\
\text { sensor } \\
\text { pin }\end{array}$ & $\begin{array}{l}\text { Arduin } \\
\text { o pin }\end{array}$ & $\begin{array}{l}\text { Temerature } \\
\text { sensor pin }\end{array}$ & $\begin{array}{l}\text { Arduino } \\
\text { pin }\end{array}$ \\
\hline $\mathrm{Vcc}$ & $+5 \mathrm{v}$ & $\mathrm{Vcc}$ & $+5 \mathrm{v}$ & Vcc & $+5 \mathrm{v}$ & $\mathrm{Vcc}$ & $+5 \mathrm{v}$ \\
\hline Ground & Ground & Ground & Ground & Ground & Ground & Ground & Ground \\
\hline Trig & D7 & Analog pin & A2 & P0 & A0 & $\begin{array}{l}\text { Digital } \\
\text { wire }\end{array}$ & D4 \\
\hline Echo & D6 & - & - & - & - & - & - \\
\hline
\end{tabular}




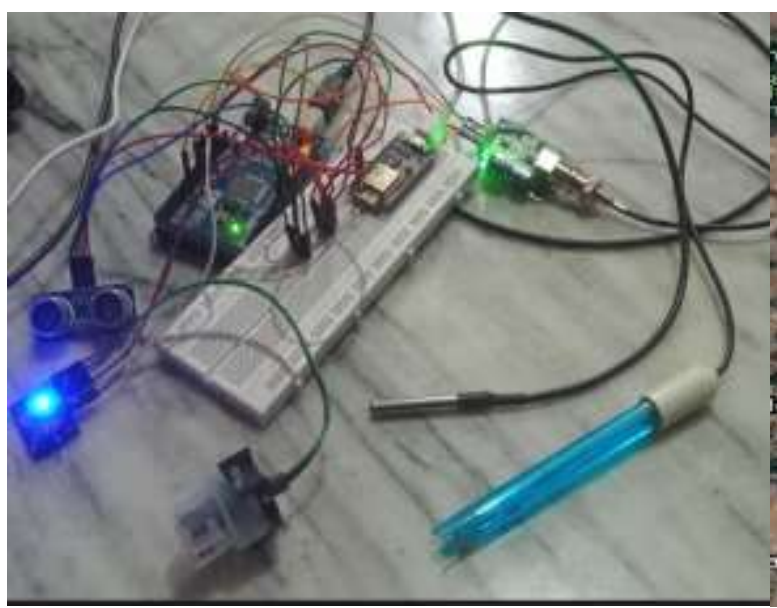

Fig 1. Hardware setup

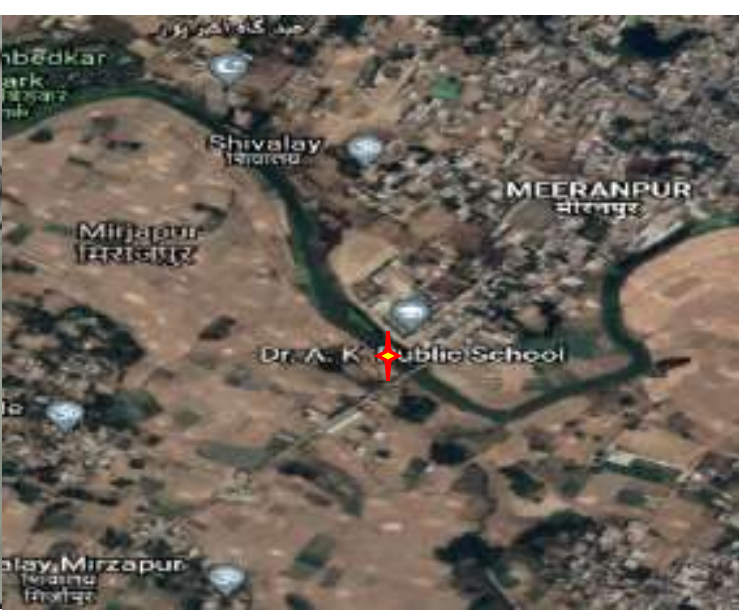

fig 2. Satellite image

\section{0 implementation and result}

With the help of the proposed smart water quality monitoring system, we investigated the water quality of the tamsa river at a site location shown in fig. 2, during the monsoon season for 15 days between the evening of $5 \mathrm{pm}$ to $6 \mathrm{pm}$. Tamsa is a tributary of the ghaghra river flowing through the various district of uttar pradesh, india, namely ayodhaya, ambedkarnagar, azamgarh, and mau. River water quality parameter data is collected by using a particular sensor at an instant, which is connected to arduino. For the analysis of data, we stored it on ms excel by using the data streamer feature of microsoft office. The average values of water parameters on a particular day, shown in fig. 3 fig. 4, fig. 5, fig.6 respectively. Fig. 3 represents the variation in river water temperature over the period. Fig. 4 represents the variation in river water level over the period. Fig. 5 represents the variation in river water ph value over the period. Fig. 6 represents the variation in river water turbidity over the period.

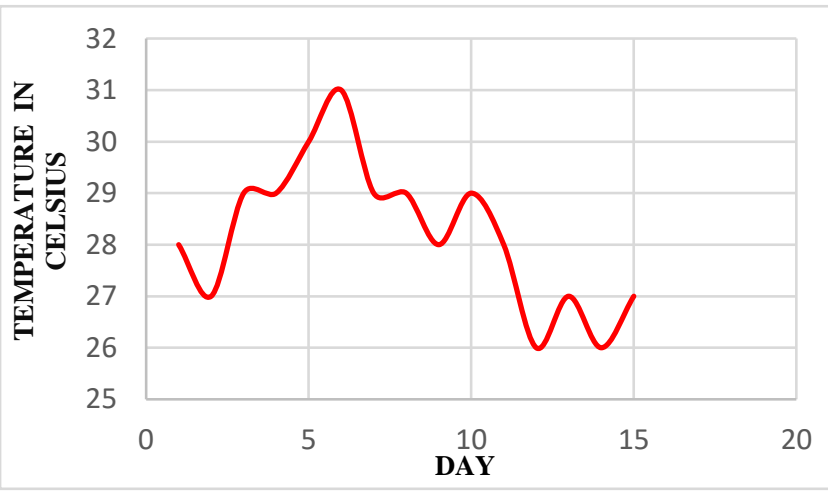

fig. 3 temperature variation

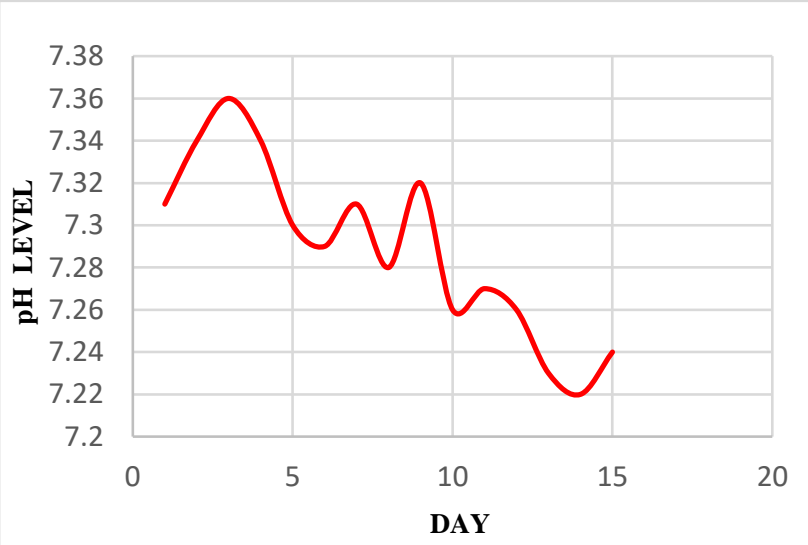

Fig. 5 ph variation

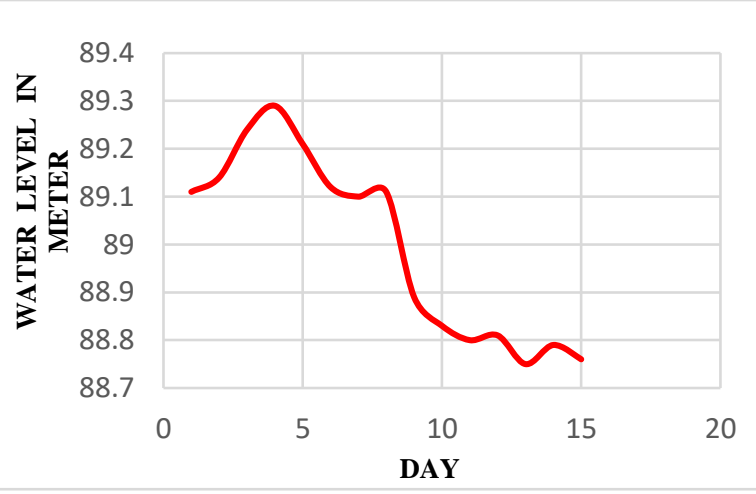

fig .4 water level variation

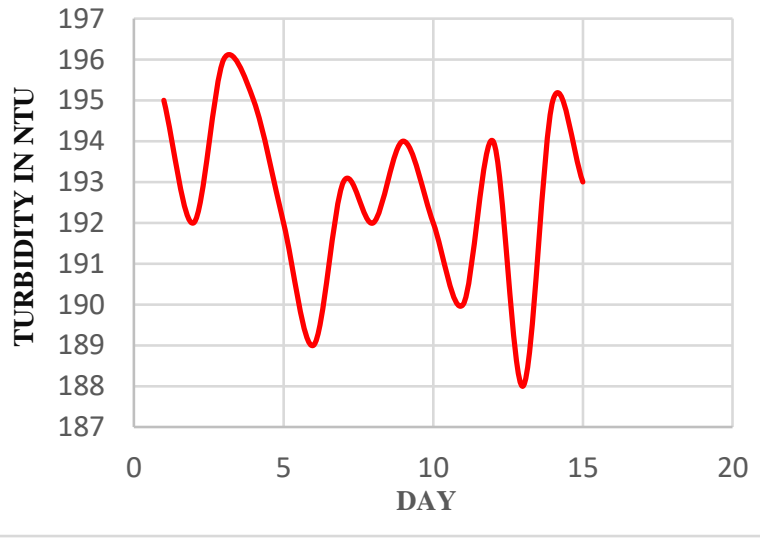

fig. 6 turbidity variation 


\title{
International Advanced Research Journal in Science, Engineering and Technology
}

\author{
Vol. 8, Issue 11, November 2021
}

DOI: $10.17148 /$ IARJSET.2021.81103

\section{CONCLUSION}

The purposed sensor-based smart water monitoring system can be used for monitoring of water quality of the river and supply water by implementing it at a strategic location, for better management of water in the future. The traditional method of water quality monitoring requires more time and money as compared to sensor-based smart water quality monitoring systems. The accuracy of the purposed water quality monitoring system is satisfactory in comparison to the traditional water quality monitoring system. The proposed water quality monitoring system can be converted into an iotbased water quality monitoring system by using a serial communication technique between node mcu and arduino. Data collected by sensor-based water monitoring systems can be used for the development of artificial intelligence-based water quality monitoring systems.

\section{REFERENCES}

[1] shruti sridharan, " water quality monitoring system using wireless sensor network" - international journal of advanced research in electronics and communication engineering (ijarece) volume 3, issue 4, april 2014.

[2] troy, s m (2002). "microbial source tracking: current methodology and future directions", applied and environmental microbiology, vol.68(12), pp.5796-5803

[3] peter, g (n. D). "swimming microbes monitor water quality", available from https://www.insidescience.org/news/swimmingmicrobes-monitorwater-qualit.

[4] r. Karthik kumar, m. Chandra mohan, s. Vengateshapandiyan, m. Mathan kumar, r. Eswaran, " solar based advanced water quality monitoring system using wireless sensor network " - international journal of science, engineering and technology research (ijsetr), volume 3, issue3, march 2014 issn: $2278-7798$.

[5] daudi s. Simbeye and shi feng yang, "water quality monitoring and control for aquaculture based on wireless sensor networks" - journal of networks, vol. 9 , no. 4, april 2014.

[6] brinda das, p.c. Jain proposed the "real-time water quality monitoring system using internet of things. Jain department of electrical engineering, school of engineering. Shiv nadar university, g. Noida-201314.

[7] nikhil r, rajender $\mathrm{r}$, dushyantha g r , m n s khadri, jagadevi ,n kalshetty, "smart water quality monitoring system using iot environment" international journal of innovations in engineering and technology (ijiet) http://dx.doi.org/10.21172/ijiet.104.12

[8] punit khatri, karunesh kumar gupta, raj kumar gupta (2020) “assessment of water quality parameters in real-time environment" sn computer science, springer nature singapore pte ltd 2020

[9] mohammad salah uddin chowdury, talha bin emran, subhasish ghosh, abhijitpathak, mohd. Manjur alam, nurul absar, karl andersson, mohammad shahadathossain, (2019). "iot based real-time river water quality monitoring system"- the 16th international conference on mobile systems and pervasive computing (mobispc).

[10] vaishnavi v. Daigavane and dr. M.a gaikwad (2017) "water quality monitoring system based on iot"- advances in wireless and mobile communications. Issn 0973-6972 volume 10, number 5 (2017), pp. 1107-1116 @ research india publications

[11] gowthamy j, chinta rohith reddy, pijush meher, saransh shrivastava, guddu kumar proposed "smart water monitoring system using iot" international research journal of engineering and technology (irjet), oct 2018

[13] asaad ahmed mohammedahmed eltaieb, zhang jian min, "automatic water level control system", international journal of science and research (ijsr) 2013

[14] saima maqbool , nidhi chandra, "real time wireless monitoring and control of water systems using zigbee 802.15.4" 5th international conference on computational intelligence and communication networks., 2013

[15] prachet varma, akshay kumar, nihesh rathod, pratik jain, mallikarjun s,renu subramaniyam, bhardhwaj amrutur, m.s.mohan kumar, rajesh sundresan, iot based water management system for a campus iee, ieee first international smart cities conference (isc2),2015.

[16] indian standard drinking water — specification (second revision) is 10500: 2012

[17] guidelines for drinking-water quality third edition incorporating the first and second addenda volume 1 recommendations. 